\title{
La vanguardia antillana de la segunda mitad del XIX y la estrategia revolucionaria continental de José Martí
}

\author{
RAMON DE ARMAS
}

Una esperanza recorría todo el mundo antillano a partir de la segunda mitad del siglo XIX: la idea de unión formal, unificación, o confederación de nuestras islas caribeñas, como instrumento para el rescate, salvaguarda y defensa de su territorio y su nacionalidad en relación con las viejas potencias coloniales europeas, y en relación -también-con los nuevos peligros que, a partir del despojo mexicano por los Estados Unidos, comienzan a evidenciarse -y a materializarseen la América no sajona.

Aunque estas ideas panantillanistas tuvieron muy disímiles variantes, en su base siempre estuvo el hecho histórico de que había sido la acción conjunta a mayor o a menor escala -tanto en la propia experiencia de las Trece Colonias del norte del continente, como en el ejemplo, más cercano a las Grandes Antillas, de la gesta libertaria hispanoamericana-, la vía que había hecho posible el nacimiento de las nuevas repúblicas americanas a la vida políticamente independiente, y a nuevas posibilidades de desenvolvimiento económico y social (cuyas características, peculiaridades y destino en ambas secciones del continente no es del caso analizar aquí).

Ahora, casi recién iniciada la segunda mital del siglo, las islas del Caribe-convertidas por el proceso colonizador, y por el propio lugar que correspondió a sus producciones dentro de la economía mundial de la época, en un fragmentado crisol donde habían confluido hombres y mujeres de las más diversas procedencias étnicas y nacionalesno parecían tener, cada una de por sí, la fuerza suficiente para alcanzar, o conservarla después de alcanzada, la ruptura definitiva con la pertenencia política a los poderes coloniales europeos. 
Su unión se manifestaba, entonces, como la vía capaz de garantizarles el logro de sus aspiraciones independentistas, y el futuro político de esa unión era históricamente factible concebirlo en términos de una integración política formal similar a la intentada por Bolívar para la parte sur del continente. O lo que es lo mismo: en términos de confederación.

Pero la idea de confederación antillana no siempre estuvo vinculada, sin embargo, al objetivo independentista. El historiador estadounidense Thomas Mattews hace ya cuatro décadas que pasó rigurosa revista (1) (aunque quizá no las agotó totalmente) a las múltiples variantes de propuestas de unificación, y a los muy disímiles argumentos y motivos que les daban origen y basamento: Thomas Jefferson, en 1801, proponiendo el área como base de refugio y asentamiento de los africanos traídos a América -y aunque sin especificar la forma de unidad-; Alejandro de Humboldt, también recién iniciado el siglo (viajó por el Caribe entre 1799 y 1804), y también sobre un basamento de carácter fundamentalmente étnico; José Alvarez de Toledo (uno de los representantes de Cuba a las Cortes de Cádiz de 1810), en propuesta efectuada al secretario norteamericano de Estado, James Monroe, en 1811, y solicitando ayuda para el establecimiento de una confederación independiente de Cuba, Puerto Rico y Santo Domingo (alegadamente en peligro de ser absorbidas por Inglaterra); Demetrio O'Daly, representante de Puerto Rico a las Cortes del segundo período de monarquía constitucional en España, con la propuesta, en 1822, de una legislatura aparte para las tres Antillas españolas.

Más de tres décadas después, y ya con el objetivo de detener los propósitos expansionistas de Estados Unidos, comenzaron a aparecer en la propia España, con el político Emilio Castelar (1855), o con el editor de la publicación madrileña La América Eduardo Asquerino (1857 y 1866), o con el también editor del igualmente madrileño periódico Las Antillas Feliciano Herreros de Tejada (1861), o con el estadista Francisco Pi y Margall (1869-1871), muy disímiles propuestas de ligas y confederaciones que aspiraban a la superviviencia del dominio colonial español en las posesiones que aún le quedaban, y el aumento de su influencia en las repúblicas que fueron sus colonias. Estas propuestas, en ocasiones, llegaban a incluir tanto a aquellas últi-

(1) THOMAS G. MATTEWS, "The proyect for a Confederation of the Greater Antilles", Caribbean Historical Review, vols. III y IV, B.W.I., diciembre de 1954. Para el presente trabajo no hemos podido consultar un importante ensayo sobre el tema del prestigioso investigador francés Paul Estrade. 
mas como a la propia metrópoli, conjuntamente con sus colonias antillanas, asiáticas y africanas.

Poco arraigo $-y$ poca resonancia- podían tener tales ideas confederacionistas o unionistas, que no rompían el marco de la depedencia o de la discriminante segregación racial. Nada en ellas podía vincularlas a las masas que poblaban las Antillas. Y nada en ellas las vinculó, hasta que no comenzaron a estar asociadas a la aspiración de ruptura con la dependencia colonial en los territorios antillanos donde ésta aún sobrevivirá, o a la consolidación y conservación de la indenpendencia más absoluta, una vez alcanzada la misma, y tanto frente a nuevos intentos de absorción europea, como frente a la ya iniciada proyección expansionista de una de las nuevas repúblicas del continente americano: los Estados Unidos.

Ello no sucedió, desde luego, hasta que iniciaron su entrada en el escenario político antillano los hombres que vinculaban ambos objetivos en sus proyectos revolucionarios, invariablemente comprometidos, además, con el logro de lo que constituía por entonces la máxima y más radical aspiración a la justicia social: la emancipación de varios cientos de miles de hombres negros aún sometidos a la esclavitud en dos de los mayores territorios insulares del Caribe: Cuba y Puerto Rico.

Fue entonces llenándose de nuevos nombres la nómina de libertadores antillanos en los que confluían (con notables similitudes, pero también con diferencias condicionadas no sólo por las circunstancias o el momento, y en relación con cuyas ideas y trayectorias están aún por realizar, en muchos casos, estudios verdaderamente profundos y definitorios) estos objetivos mayores a los que la época convocaba en la fragmentada región (2): los puertorriqueños Ramón Emeterio Betances, Eugenio María de Hostos, Segundo Ruiz Belvis, Francisco Basora; los dominicanos Gregorio Luperón, Ulises Espaillat, José María Cabral, Pedro F. Bonó; los haitianos Nissage Saget, Fabre Geffrard, Louis Joseph Janvier, Antenor Firmin; los cubanos Juan Manuel Macías, Francisco Vicente Aguilera, Antonio Maceo, Máximo Gómez (cubano y dominicano, ambos por derecho propio), y José Martí.

(2) La ofrecida constituye, sin dudas, una nómina imperfecta e incompleta: en ella faltarán nombres que con pleno derecho podrían integrarla; en ella, también, el estudio y la profundización ulteriores demostrarán la pertinencia o no de la presencia de algunos de los aquí mencionados, sin que ello, desde luego, disminuya sus méritos dentro de la Historia antillana. 
Había precursores gloriosos en cada una de las islas: son nombres perdurables, y de todos conocidos. Pero en la casi totalidad de estos hombres que ahora tomaban en sus manos la obra de completar o consolidar la independencia antillana, fue también tomando cuerpo -con intensidad y características no siempre coincidentes- un conjunto de ideas rectoras, de proyecciones y posturas esenciales, que les acercaban, les identificaban, y determinaban su acción unida; y que hoy -a la distancia que la historia ya permite- se nos presentan como indiscutibles integrantes de una verdadera vanguardia revolucionaria antillana de la segunda mitad del siglo XIX.

Otros -los que les habían precedido y sirvieron de puente a sus firmes posturas independentistas y de justicia social- habían desempeñado papeles extraordinarios en la larga lucha por la independencia de los diversos territorios antillanos. Y otros más seguirían ahora a estos nuevos hombres, y habrían de morir, también, compartiendo los mismos principios de esta vanguardia. Ni los unos ni los otros son en modo alguno separables de la heroica trayectoria de la misma, ni de la propia historia de nuestras islas, si no es con el único fin de poder determinar -a través del análisis del pensamiento y de la acción de las figuras mayores que el dieron origen- las peculiaridades de sus concepciones y, sobre todo, los principios de los que partieron (y que son los que aún pueden tener amplia vigencia y validez para nuestras luchas de hoy) en su búsqueda de soluciones al conjunto de graves males económicos, políticos y sociales que la época lanzaba sobre las grandes masas de la población antillana.

Como señala el notable historiador dominicano Emilio Cordero Michel (3), hasta hoy numerosos historiadores habíamos considerado la génesis de la idea de confederación antillana (en cuanto a idea vinculada al logro y conservación de la independencia absoluta de nuestras islas) como resultado inmediato y directo de las previsiones de los más destacados revolucionarios puertorriqueños del siglo XIX: Ramón Emeterio Betances y Eugenio María de Hostos. Más de una vez, también, se le había atribuido a José Martí la paternidad de los anhelos unionistas antillanos (4).

(3) CORDERO MICHEL, Emilio: "El antillanismo de Luperón", ponencia presentada al VI Congreso Dominicano de Historia, Santo Domingo, República Dominicana, 1989.

(4) Así lo plantea Eugenio María de Hostos en "El testamento de Marti", en: Hostos y Cuba, recopilación y prólogo de Emilio Roig de Leuchsering, Ed. de Ciencias Sociales, Instituto Cubano del Libro, La Habana [s.f.], p. 259. 
En realidad, no hubiera resultado sorprendente un origen puertorriqueño de tales aspiraciones. En primer lugar, por el inclaudicable afán independentista, la sostenida vocación antillana, y las mil veces demostrada solidaridad internacionalista -a través de la ininterrumpida dedicáción de sus propias vidas- de los próceres borinqueños en cuestión. En segundo lugar, por la insuperable (y, en nuestra opinión, feliz) necesidad histórica de Puerto Rico de unir su lucha y sus destinos a los de las islas vecinas, como consecuencia del relativo aislamiento de la menor de nuestras Antillas Mayores, de su entonces escasa población, y del aún incipiente desarrollo de su economía en comparación, por ejemplo, con el de la otra posesión española del Caribe insular llamada a compartir con ella la completación de la brega independentista: Cuba.

Y aunque no se trata, en modo alguno, de intentar detectar supuestas prioridades y preeminencias en los valores creativos de nuestros comunes libertadores, sí resulta importante para los objetivos del presente trabajo definir las circunstancias históricas que dieron lugar al nacimiento de una concepción que habría de desempeñar un papel de notable trascendencia en el pensamiento y en la acción revolucionaria de los pueblos antillanos.

Explica el mencionado historiador dominicano la íntima relación entre el origen -en enero de 1864- del ideario unionista, confederacionista o panantillanista, y el proceso revolucionario de la guerra restauradora iniciada en República Dominicana en 1863, desprendiéndose, "como fruto natural y lógico, del pensamiento y la acción revolucionaria de los prohombres de la Restauración: Mella, Espaillat, Bonó, Rojas, Grullón, Rodríguez, Objío, Polanco y, particularmente, Luperón" (5), así como del presidente haitiano Fabre Geffrard, firme apoyo de la lucha dominicana contra las fuerzas sustentadoras de la anexión a España. "Fueron ellos -afirma-quienes lanzaron la idea de la unidad insular domínico-haitiana, primero, y de las Antillas, después". Tanto Betances como Hostos reconocieron esta primacía en el surgimiento de las concepciones panantillanistas, afirmando el primero que República Dominicana fue (y citamos apoyándonos en el trabajo de Cordero Michel) "la nación generatriz de la nacionalidad antillana"; y ratificando el segundo su consideración de que era "la nación iniciadora de la nacionalidad antillana y del plan de la Confederación".

(5) CORDERO MICHEL, op. cit., p. 6. 
Ello, desde luego, no excluyó que -por su propio camino, y acorde con las circunstancias históricas de su patria natal- en el prócer puertorriqueño Ramón Emeterio Betances hubiran nacido, ya desde sus años de estudiante en Francia a finales de la década del 40, y según su propio tesimonio (6), muy firmes sentimientos y activos compromisos a favor de la independencia tanto de Puerto Rico como de Cuba, y por la afirmación de la libertad en el resto de las Antillas. Tal sería uno de los fundamentales puntos de apoyo de su ininterrumpido quehacer revolucionario ulterior, que le llevaría -ya en la segunda mitad de la década del 60 - a coordinar sus proyectos y su intensa actividad independentistas con los revolucionarios dominicanos, y (según fuentes historiográficas españolas de la época) también con algunos cubanos. Desde entonces, toda su acción organizadora y concientizadora fue puesta al aservicio de la eventual creación de una confederación antillana.

A esta idea llegaría Eugenio María de Hostos por un camino totalmente distinto, evidentemente vinculado a una extensa permanencia en España y a la influencia de los planteamientos confederacionistas alli surgidos (a los cuales hemos hecho referencia anterior).

En efecto, en su memorable discurso de 20 de diciembre de 1868 en el Ateneo de Madrid (7) -en el cual se hace manifiesta su ruptura definitiva con toda esperanza de recibir de la república liberal recién inaugurada en España las libertades que Cuba y Puerto Rico (en Yara y en Lares) ya habían comenzado a exigir con las armas en la manoHostos aún había hecho mención, aunque con evidente carencia de fe y a manera de recriminación final, del reclamo de dar nacimiento, en plano de igualdad, a una unión federal de España y las Antillas españolas.

Su íntima decisión, perceptible ya en aquel discurso, de romper con España y trabajar por la libertad de las Antillas, se materializaría inmediatamente, al llegar a Nueva York en enero de 1869 y vincularse a la alli existente Sociedad Republicana de Cuba y Puerto Rico, fundada en 1865 por separatistas de ambas islas y a través de la cual laboró activamente, en unión de Betances y Basora, por la promoción y con-

(6) EMETERIO BETANCES, Ramón: "Recuerdos de un revolucionario", en Ramón Emeterio Betances, selección y prólogo de Emilio Godínez y Haroldo Dilla, Casa de la Américas, La Habana, 1983, p. 301.

(7) HOSTOS, Eugenio María de: "Discurso y rectificación, en la sesión celebrada por el Ateneo de Madrid en la noche del sábado 20 de diciembre de 1868", en sus Obras, Compilación y prólogo de Camila Henriquez Ureña, Colección Pensamiento de Nuestra América, Casa de las Américas, La Habana, 1976. 
secución de los ideales confederacionistas. Los integrantes de la Sociedad (por cierto, no muy numerosos) y -como veremos- una buena parte de la emigración cubana y puertorriqueña radicada en Nueva York, Filadelfia y Nueva Orleáns, también los compartían.

La Sociedad Republicana de Cuba y Puerto Rico estaba presidida por Juan Manuel Macías y constituye una de las primeras manifestaciones recogidas por nuestra historiografía en relación con la presencia de ideas confederacionistas en independentistas cubanos del período. Entre otras figuras vinculadas a su dirección se hallaban Pedro Santacilia, Cirilo Villaverde, Ramón Roa, Juan Clemente Zenea y Ramón Arnao (8).

Pero, en realidad, la lucha iniciada en la Isla el 10 de octubre de 1868 había estallado sin relación alguna con los emigrados cubanos radicados en Estados Unidos. Y, por otra parte, el propio Betances ha dejado constancia documental (9) de que al frustrado alzamiento de Lares, ocurrido en la isla hermana sólo 17 días antes, no había precedido coordinación alguna entre los revolucionarios de una y otra Anti1la. Solamente la historiografía española ya mencionada ha afirmado que en febrero de 1868 le fue ocupada al "general negro dominicano Boom, natural de Santo Domingo" documentación demostrativa de que el mismo conspiraba con independentistas de Cuba y Puerto Rico "para constituir una federación republicana en todas las Antillas", y de que se preparaban resultados importantes para formar una confederación de Puerto Rico y Cuba con Santo Domingo y Haití (10).

En la organización y desencadenamiento de la insurrección cubana habían desempeñado el papel rector Carlos Manuel de Céspedes (11) y

(8) Ver:' CRUZ MONCLOVA, Lidio: Historia de Puento Rico (siglo XLX), t. 1, Editorial Universitaria, Río Piedras, 1970, p. 435.

(9) Carta de Ramón Emeterio Betances a Manuel Sanguily, París, 11 dè agosto de 1891. Fotocopia en poder del autor.

(10) PEREZ MORIS, José y CUETO, Luis: Historia de la insurrección de Lares, Barcelona, 1872 , p. 52 , y p. $65-66$ (nota 3)

(11) Hay reflejos de su preocupación e interés por las perspectivas independentistas de Puerto Rico, así como de su aspiración a un acercamiento y coordinación entre las naciones antillanas. En ese mismo sentido, por ejemplo, el 2 de septiembre de 1872 anota en su diario: "Empieza Puerto Rico a contribuir para la guerra de Cuba, como ésta para la de Santo Domingo. ¡Buen agüero!”. Pero resulta evidente que el centro de su acción y de su pensamiento -la conducción de la lucha insurreccional desatada en Cuba, y su dirección por entre las numerosas dificultades internas y externas que la misma debió enfrentar- no parece haber dejado lugar, entre otros factores, y a diferencia de lo sucedido con otras figuras, para propiciar una acción conjunta y unitaria con el resto de las Antillas. Ver, por ejemplo: Carlos Manuel de Céspedes, Escritos, Compilación de Fernando Portuondo del Prado 'y Hortensia Pichardo Viñals, Ed. de Ciencias Sociales, La Habana, t. 1, p. 357, 375 y 386. 
Francisco Vicente Aguilera. Solamente en el caso de este último hay pruebas documentales de haber concebido aspiraciones y propósitos de que la independencia de Cuba condujera a la de Puerto Rico. Estimaba Aguilera que "unidas estas dos islas por un pacto federal que les aseguraba mutuo apoyo" (12) y que les viabilizara un rápido engrandecimiento, no tardarían en sentirse atraídas a ellas Santo Domingo y Haití, y "unidas las tres islas, formarían un núcleo poderoso que gradualmente iría creciendo con la atracción del archipiélago de las Antillas", hasta constituir la confederación antillana que Aguilera contemplaba para los tiempos por venir. Su correspondencia posterior (1873) con el diputado por Guadalupe, Germán Cassé (13), demuestra el alcance que la misma debía tener, al incluir también a las Antillas Menores. Aunque en el mismo año Aguilera aseguraba en París al propio Cassé que la Gran Federación Antillana era "no sólo la más cara aspiración de su alma, sino la de todos los hombres pensadores de su país" (14), no hay hasta el momento, en realidad, evidencias historiográficas que permitan ratificar una aseveración tan generalizadora como ésta en relación con sus contemporáneos.

Sin embargo, en octubre de 1874 el periódico independentista cubano El Republicano, publicado en Cayo Hueso (Estados Unidos), insertaba una carta de Betances al presidente de la agrupación de emigrados cubanos "Sociedad de Artesanos de Key West" en la que afirmaba conocer las ideas confederacionistas de dicha asociación, y le informaba de su coincidencia con las de la "Liga de las Antillas" fundada en París, pocos meses antes, por Luperón y él (15).

También en esos años (octubre de 1876), otra publicación independentista cubana, La Voz de la Patria, editada en Nueva York, señalaba en un editorial de contenido programático tener entre sus objetivos "la creación de una potencia o personalidad internacional por medio de la Confederación de las Antillas" - de proyección latinoamericanista-, con el fin de "buscar elementos materiales y morales con que robustecer reciprocamente nuestro poder político, facilitar nuestro

(12) AGUILERA ROJAS, Eladio: Francisco Vicente Aguilera y la Revolución de Cuba de 1868, La Moderna Poesía, La Habana, 1909, t. 1, p. 36.

(13) Carta de Francisco Vicente Aguilera a Germán Cassé, Nueva York, 16 de mayo de 1873, Archivo Nacional, Fondo Donativos y Remisiones, caja 660, n..$\stackrel{1}{1}$. Agradecemos este documento al investigador Emilio Godínez.

(14) LUZ LEON, José de la: La diplomacia de la manigua, Ed. Lex, La Habana, 1947, p. 74 (nota).

(15) EMETERIO BETANCES, Ramón: "Carta interesante", en El Republicano, Cayo Hueso, 31 de octubre de 1874, año VI, n. ${ }^{\circ}$ VIII, p. 1. Subrayado en el original. 
engradecimiento en todos los sentidos, y hacernos respetables y fuertes" (16). Días después (17), el periódico comienza a publicar cartas de adhesión de grupos de emigrados cubanọ y puertorriqueños de distintas localidades estadounidenses, entre los que se encuentran el ya mencionado Francisco Vicente Aguilera, el general Manuel de Quesada (muy cercano a Carlos Manuel de Céspedes), Eugenio María de Hostos, y otras figuras que tres lustros más tarde tendrían alta importancia en la preparación de una nueva etapa de lucha armada revolucionaria en Cuba, a cuyo frente vendría finalmente a estar José Martí (18).

En ese mismo mes, el propio periódico publicó, en números sucesivos (19), el programa del club revolucionario "Los Independientes", de emigrados de ambas Antillas en Nueva York. Este programa contiene bases similares a las reseñadas más arriba, y destaca los objetivos confederacionistas contemplados como parte de su actividad independentista.

Sólo dos años después de estas importantes huellas documentales, aparecen las más tempranas evidencias conocidas de que uno de los principales jefes revolucionarios del siglo XIX cubano, participante de trascendencia mayor en la Guerra de los Diez Años y futuro continuador de la lucha independentista, Antonio Maceo, llegaba a la idea de unión antillana por un camino directamente vinculado a las necesidades prácticas -y políticas- de los objetivos libertarios del pueblo cubano revolucionario. En efecto, al hacer públicas las ideas que le mueven a él y a otros jefes revolucionarios a no aceptar el claudicante Pacto del Zanjón y efectuar su famosa Protesta de Baraguá, Maceo propone que "debemos formar una nueva república asimilada a nuestra hermana la de Santo Domingo y Haití" (20).

A finales de 1880, apenas dos años y medio después de la proclama en que exponía esas ideas -y ya iniciado en Cuba el breve período de reactivación de la lucha armada conocido como "la Guerra Chiquita"-, fue descubierta una conspiración que cubría una extensa zona de la región oriental y que se denominaba "Liga Antillana". Según

(16) La Vox de la Patria, Nuev York, 6 de octubre de 1876, año I, n. 31, p. 2.

(17) Ibid., 13 de octubre de 1876 , a I, n.ำ 32, p. 2. Continuó en las siguientes entregas.

(18) Se trata fundamentalmente, entre otros, de José Francisco Lamadriz, Ráfael de Castro Palomino y Manuel de la C. Beraza.

(19) La Voz de la Patria, Nueva York. Entrega citada en nota 17, y entregas sucesivas.

(20) MACEO, Antonio: "A los habitantes del Departamento Oriental", en Ideología Politica, La Habana, 1959, t. 1, p. 101-102. Entre los firmantes se hallaban jefes revolucionarios tan impotantes como Flor Crombet, Vicente Garcia, Guillermo Moncada y Pedro Martínez Freire. 
fuentes historiográficas españolas (de hecho, las únicas existentes) (21), al frente de la misma figuraba, conjuntamente con Antonio Maceo, el dominicano Gregorio Luperón. La conspiración tenía como propósito "fundar (...) la federación de Cuba, Puerto Rico y Santo Domingo". Siguiendo la política española de acusar de "guerra de razas" a todo intento independentista cubano, la historiografía colonialista de la época afirma que "el programa de la "Liga negra Antillana" es el predominio de la raza de color en las Antillas". Más de 300 negros y mulatos de la región oriental fueron deportados sin previo juicio, mientras que los numerosos blancos involucrados en esta conspiración de objetivos independentistas y confederacionistas fueron dejados en libertad por las autoridades españolas, con el reconocido objetivo de propiciar divisiones entre los cubanos negros y los cubanos blancos (22).

Muy poco tiempo después, hacia 1886, una de las más altas figuras de la independencia antillana, el general cubano-dominicano Máximo Gómez, dejará singular constancia de sus criterios en relación con la unificación de nuestros territorios del Caribe insular.

En efecto, es aproximadamente de ese año que data un interesante y peculiar escrito, titulado "El Porvenir de las Antillas" (23), que recoge las ideas que sobre el conjunto de nuestras islas tenía -en los momentos en que acomete la organización de una nueva guerra de liberación en Cuba- este principalísimo jefe revolucionario. Al escribirlo, el general indepedentista se sitúa hipotéticamente a mediados del siglo $X X$, y narra detalladamente -como pasado ya histórico- lo que

(21) PIRALA, Antonio: Anales de la guerra de Cuba, Madrid, 1898, t. 3, p. 877. Ver también su Historia contemporánea: Segunda parte de la Guerra Civil, Madrid, 1895, t. 6, p. 388-389, y Francisco J. MOYA, Consideraciones militares sobre la campaña de Cuba, Madrid, Imprenta del Cuerpo de Artillería, 1901, p. 232. También el historiador cubano Gerardo Castellanos G. hace mención de la conspiración en su: Panorama Histórico, ensayo de cronologia cubana, La Habana, Ucar, García y Cía., 1934, vol. 2, p. 880.

(22) BACARDI, Emilio: Crónicas de Santiago de Cuba, Santiago de Cuba, 1923, t. 6, p. 367-368, (nota 345).

(23) GOMEZ BAEZ, Máximo: "El Porvenir de las Antillas", Canteles, La Habana, n. 46 y 47, de 15 y 22 de noviembre de 1942. Reproducido por el autor en: Revista de la Biblioteca Nacional José Martí, La Habana, n.․2, mayo-agosto de 1986.

Debemos la noticia acerca de este trabajo al investigador César García del Pino. Es digno de destacar que hacia 1887, precisamente en los mismos años en que se calcula fue escrito, Máximo Gómez acudía a Ramón Emeterio Betances en busca de apoyo para propiciar un movimiento revolucionario conjunto de Cuba y Puerto Rico (ver: Emilio Godínez y Haroldo Dilla, "Prólogo", en su: Ramón Emeterio Betances, ed. cit., p. 41. 
entonces aspiraba a que fuera el porvenir del conjunto de las islas antillanas: una gran revolución que las involucrase a todas, junto con una parte de la cuenca del Caribe. Según Máximo Gómez, esta revolución -que se iniciaría en Cuba y Puerto Rico- daría por resultado la sustitución de las clases altas hasta entonces en el poder por las clases populares, integradas mayoritariamente en nuestras tierras por negros y mestizos, y que contarían con el apoyo de una amplia parte de la población blanca. El propósito -dice Gómez-se extendió entre los pueblos antillanos facilitado por "la amistad, por la proximidad e identidad, con Santo Domingo, Haití, Jamaica, La Trinidad, las Guyanas inglesas y todo el archipiélago de las Bahamas". En poco tiempo, afirma la raza de color (incluidos los negros del sur de los Estados Unidos) "entrevió en las Antillas no solamente un refugio para vivir como hombres, sino una futura patria para sus hijos". En muy poco tiempo -continúa- cundió "por toda la América antillana la idea de "la revolución de los desheredados". Y ello representó la celebración de "la perpetua alianza entre las Antillas, reanudando los lazos de antiguo rotos por la conquista".

Aunque no llega a aclarar en su relato cuál fue la forma política que adoptó esa alianza, sí precisa que, antes de la que ha llamado la revolución de los desheredados, "las Antillas hermanas entre sí no tenían comunicación; y se vivía en el aislamiento en medio del mar Caribe". Ahora, una vez realizada aquella revolución, "la historia nos está probando que del pasado atraso en que por tantos años vivieron estacionadas estas Antillas, su principal causa consistía en el lastimoso y contranatural aislamiento que entre todas ellas existía". Sin embargo, hacia la última década del siglo, ya Máximo Gómez no parece tener esperanzas de una unión formal' de nuestras repúblicas, y previendo -en nuevas circunstancias continentales- nuevas formas de unidad de los territorios antillanos, ahora reclama: "Sueño con una ley que con muy insignificantes restricciones declararse (y lo mismo con Puerto Rico cuando fuese libre) que el dominicano fuese cubano en Cuba, y viceversa (24).

Hemos querido detenernos en las diversas manifestaciones de la idea de unión o confederación antillana en los dirigentes revolucionarios del período por los motivos que a continuación señalamos.

Muy en primer lugar, porque -como se ha hecho evidente en el caso del dominicano Gregorio Luperón- si bien el panantillanismo tuvo su origen en la urgencia defensiva, tanto de Haití como de Santo

(24) GOMEZ BAEZ, Máximo: "Odisea del General José", en su: Revoluciones... Cuba y Hogar, Compilación de Bernardo Gómez Toro, La Habana, 1927, p. 95-96. 
Domingo, ante los intentos españoles de recuperar posiciones en las Antillas (con la complicidad de importantes factores políticos, sociales y económicos actuantes, internamente, en ambas islas), su fuerte y perdurable arraigo estuvo vinculado de inmediato -ante todo, y expresado de manera explícita por el propio Luperón-, a la aparición del nuevo y alarmante peligro representado, desde los inicios mismos de la década del 60, e interrumpido sólo por el estallido de la Guerra de Secesión (25), por las proyecciones anexionistas de Estados Unidos en relación con los territorios insulares caribeños, especialmente Cuba, Haití-Santo Domingo y Puerto Rico.

La experiencia del despojo a México, desde luego, también había hecho evidentes la inmediatez del riesgo, y la perentoriedad de toda acción unida capaz de conjurarlo.

Pero, por otra parte, tampoco en relación con las intenciones estadounidenses faltaban en nuestras sociedades -como no habían faltado en el caso de la anexión dominicana a España, ni faltarían después- suficientes elementos antinacionales dispuestos a la complicidad interesada y a la entrega -que es como la desaparición- de la nacionalidad. $\mathrm{Y}$ a todos los mencionados factores estaría estrechamente ligado, en nuestra opinión, el desarrollo ulterior de lass ideas unionistas o confederacionistas en las Antillas, y en sus principäles, más genuinos y previsores representantes.

Pero, en segundo lugar, resulta perfectamente perceptible que en los elementos vocados a dicha unión y capaces de llevarla a cabo -es decir, en los iniciadores, los promotores y los continuadores del panantillanismo- confluían, además, un determinado número de características comunes, muy peculiares y muy específicas, que condicionaban y hacian posible su disposición unionista, y que les diferenciaban radicalmente de otros protagonistas políticos del período. Son precisamente estas características comunes asociadas a su panantillanismo las que permiten considerarles hoy como integrantes de una verdadera vanguardia revolucionaria antillana de la segunda mitad del siglo XIX (26), y las que han determinado que sus ideas y sus figuras $-\mathrm{y}$, sobre todo, sus principios y puntos de partida- tengan hoy vigencia y validez en el ejemplo y en la búsqueda de soluciones a las nuevas (y también graves) situaciones que afectan al Caribe insular contemporáneo a nosotros.

(25) CORDERO MICHEL, op. cit., p. 3.

(26) En ibíd., p. 25, el autor hace mención de posiciones de Luperón al respecto. 
La presencia de estas características específicas resulta muy evidente en las figuras que más fuertemente han trascendido a nuestra contemporaneidad -y que son, desde luego, las más estudiadas-. En relación con otros (muy en particular, algunos dirigentes haitianos que aún hoy resultan insuficientemente conocidos), solamente la profundización ulterior en la investigación histórica de sus trayectorias, sus circunstancias y sus ideas podrá sacar a la luz la confluencia en ellos de tales rasgos comunes que, en nuestra opinión (y en ello seguimos ideas concebidas y expresadas oralmente, sin que nunca alcazara a desarrollarlas por escrito, por el tempranamente fallecido historiador y antillanista cubano Emilio Godínez Sosa) pueden sintetizarse del siguiente modo:

1., Todos ellos actúan de acuerdo con una definida conciencia de antillanía que se expresa -aunque con distintos matices- no sólo en el reconocimiento de nuestras islas como dotadas de unidad tanto geográfica como histórica, sino como también dotadas de unidad cultural, y -sobre todo- de unidad nacional: es decir, como un conjunto en el cual tanto la similitud histórica como los semejantes componente étnicos han llevado a la conformación, o a la prefiguración, de una nacionalidad antillana (que en algunas de estas figuras será considerada, solamente, como una raza antillana).

2. Se expresa además esta conciencia de antillanía en el reconocimiento de la necesidad de eventual integración o unión -bajo formas y maneras no siempre coincidentes- de los territorios o países que componen el conjunto, no sólo para defenderlo (como ya se ha señalado) de todo peligro de absorción o asimilación externa, sino también para garantizar un más rápido progreso individual y colectivo de sus entidades. Ello no implicaba, sin embargo, que vieran a los territorios insulares del Caribe como separados, diferenciados, o desvinculados, del resto del mundo latinoamericano. Muy por el contrario, en todos estaba presente una definida conciencia de pertenencia al conjunto mayor de países al sur del río Bravo (lo que José Martí llamaría Nuestra América), hacia cuya eventual integración coadyuvaría de manera eficiente la unión o confederación de los territorios antillanos, y en relación con los cuales la independencia y unidad de las islas debía servir de valladar para garantizar la defensa, consolidación y conservación de la independencia de aquella parte del continente. Debería hacer posible -además- el equilibrio de los dos componentes disímiles del mismo, sometido el uno a las disolventes proyecciones expansionistas del otro. En ocasiones, esa función de equilibrio podía referirse, también, al equilibrio general -político y económico- del mundo. De ese modo, además de representar las más consecuentes posiciones patrióti- 
cas en sus respectivos países (muy vinculadas a la consolidación, cuando no a la salvación, de la nacionalidad), en ellos este patriotismo confluye certera y estrechamente con las genuinas posiciones internacionalistas implícitas en la asunción de la defensa del conjuno insular antillano, y de la gran patria latinoamericana de la cual se consideraban hijos, y por la cual igualmente lucharon mediante todas las vías a su alcance.

4. Demuestran, y practican $-\mathrm{y}$ a esta práctica está íntimamente ligado el consecuente patriotismo más arriba señalado- un alto grado de compromiso no sólo contra los remanentes de la esclavitud en los territorios antillanos, sino con los sectores y grupos sociales más oprimidos y desposeídos de nuestras sociedades (altamente polarizadas en la distribución de la riqueza y la cultura, y profundamente mestizadas), con cuya determinante partipación contaban, y para los cuales perseguían la solución de los graves males sociales que sobre ellos pesaban. En este sentido, manifiestan un profundo democratismo que generalmente se expresa tanto en sus posturas teóricas como en su propia práctica revolucionaria, independientemente de su procedencia clasistas personal. Ello no significó, sin embargo, un rompimiento con las clases y sectores que en el período en cuestión tenían el privilegio de la cultura, o determinado grado de dominio sobre los recursos y medios productivos fundamentales del país. Por el contrario, la participación activa de los sectores sanamente nacionalistas de las incipientes burguesías antillanas estaba indiscutiblemente implícita en la vida nacional independiente por la cual bregaba esta vanguardia, y en los procesos políticos que (por una vía o por otra) debían garantizar el cumplimiento de los objetivos comunes perseguidos para el bienestar y la prosperidad de los pueblos que integraban el conjunto antillano.

5. Sin embargo de lo anterior, en varios de las más destacadas figuras incluidas en este grupo de vanguardia revolucionaria es posible percibir algunos aspectos que, en ese sentido, merecen un destaque particular:

Primero, La certidumbre de que los sectores adinerados de sus prespectivas sociedades podían llegar a ajercer un alto grado de complicidad con los factores externos interesados en la incorporación o la abosorción del país y de la nacionalidad, y no estaban en modo alguno vocados -o demostraban estar, según el caso, abiertamente opuestos- a la realización de las alteraciones o cambios en el ordenamiento económico y social vigente, que estaban generalmente implícitos en la propia persecución de nuevas vías de desenvolvimiento económico inherentes a los objetivos políticos y sociales de los hombres que componían la vanguardia revolucionaria antillana. Practicaban, por 
tanto, un sistemático alejamiento de los respectivos procesos independentistas y de reafirmación democrática, según el caso, cuando no adoptaban posiciones de contenido francamente antinacional.

Segundo, la coincidencia en el reclamo de un considerable grado de originalidad y autoctonía en relación con las soluciones a proponer y adoptar, los caminos a seguir, y las instituciones a establecer, rechazando la copia acrítica de modelos creados para realidades ajenas a las antillanas e-incluso-a las latinoamericanas.

Tercero, un notable alejamiento, consciente o no (y que en algunos casos puede haber llegado al rompimiento), con las variantes o manifestaciones entonces conocidas del liberalismo. Ello tenía su origen en el constante enfrentamiento a las posiciones agresivas del liberalismo español y, en general, europeo (26), y del liberalismo estadounidense, prohijador o propulsor de acciones expansionistas contra los territorios antillanos, así como de los llamados partidos liberales (autonomistas, reformistas o anexionistas) dentro de sus respectivas sociedades, a los cuales les fue necesario enfrentarse, incluso, por medio de las armas. Pensamos que este aspecto, que reviste suma importancia, amerita rigurosos análisis particulares que permitan alcanzar una caracterización certera y válida de su pensamiento.

El caso específico de José Martí es quizá uno de los que más estudio y atención hayan recibido entre los miembros de esta vanguardia revolucionaria antillana de la segunda mitad del XIX. Y quizá lo sea porque -en las circunstancias históricas de su época, de su patria natal, y de su propia vida y persona- en Martí confluyeron mayores posibilidades de elaborar y proponer una estrategia revolucionaria continental cuyos basamentos y soluciones conservan hasta hoy una sorprendente vigencia.

Sus ideas, ciertamente, arrancan de similares puntos de partida que las de los otros integrantes de esta vanguardia, quienes necesariamente deben haber influido (en grado y magnitud aún no determinados) en el desarrollo ideológico y político del cubano. Son aún muy poco frecuentes los trabajos de análisis que se hayan planteado el estudio de las interrelaciones e influencias mutuas entre nuestros antillanos mayores. Quizá los casos más evidentes y conocidos sean los de las relaciones entre Luperón, Hostos y Betances (27), los trabajos en que

(27) Ver, por ejemplo: RODRIGUEZ DEMORIZI, Emilio: Luperón y Hostos, Editora Montalvo, C.T., Santo Domingo, 1939; RAMOS MATTEI, Andrés A.: Betances en el ciclo revolucionario antillano: 1867-1875, Instituto de Cultura Puertorriqueña, San Juan, 1987, entre otros. 
se hace referencia a las coincidencias de Máximo Gómez, casi siempre casuales y vinculadas a sus permanencias en Santo Domingo, con figuras como Hostos y Luperón (28), o a las vinculaciones entre este último y Antonio Maceo (29). Pero, en su conjunto, no parecen ser, aún, suficientes. Y ello resulta particularmente sensible en lo referente a José Martí, ya que a pesar de la precocidad en el inicio de su actividad independentista y en la conformación de un pesamiento revolucionario de gran radicalidad, su aún muy escasa edad en los momentos en que ya estos luchadores habían alcanzado, o alcanzaban, planos dirigentes en el movimiento revolucionario antillano, tiene necesariamente que haber condicionado un determinado grado de conocimiento -que aún debe ser precisado- de las ideas de muchos de estos grandes hijos de las Antillas que le precedieron en su quehacer, y una segura influencia de su pensamiento en la conformación dè las ideas del cubano.

Valga solamente un elocuente ejemplo. El 23 de enero de 1869 -solamente cinco días antes de cumplir Martí los 16 años de edad-, y posibilitado por un período de relativa y muy condicionada libertad de imprenta establecido en la colonia cubana por la máxima representación de la Metrópoli en ella, vio la luz un modesto periodiquito de solamente ocho páginas que llevaba el definitorio nombre de $L a$ Patria Libre. Sus editores -entre los cuales se hallaba aquel jovencito todavía quinceañero- supieron apreciar el valor del discurso (que ya hemos mencionado) en que Eugenio María de Hostos había definido ante el Ateneo de Madrid, hacía solamente un mes, sus posiciones anticolonialistas. No cabía en las escasas páginas del pequeño tabloide -y así lo lamentaban sus editories- el texto completo de la pieza: por ello, solamente podían publicar, "seguros de agradar a nuestros lectores", las Rectificaciones que constituian la parte central y determinante de la misma. ¿Quién podría dudar, entonces, que el pensamiento y las posiciones de Hostos estaban, desde momentos tan tempranos en la vida de Martí, incidiendo en el desarrollo de sus ideas? ¿Quién podría afirmar que durante su primera deportación a España en 1871 -que se extendería desde sus 17 hasta sus 21 años de edad-, Martí no haya conocido, en su concidencia y contactos con otros deportados procedentes de la isla hermana, las acciones y los escritos (que ya por entonces se publicaban en Francia) de Ramón Emeterio Betances, residente en París desde 1872? ¿Cuánto no puede haber sabido acerca de

(28) Ver, por ejemplo: RODRIGUEZ DEMORIZI, Emilio: Papeles dominicanos de Máximo Gómez, C.T., Santo Domingo, [s.f.].

(29) Ver, por ejemplo: MACEO, Antonio: Ideología política, La Habana, 1950, t. 1. 
los independentistas y confederacionistas antillanos durante su inmediatamente posterior exilio en México, durante los años 75 y 76 ?

Tal estudio es necesario, y se hará. Pero no parece haber lugar para la duda en lo referente a la similitud y coincidencia con los de los otros integrantes de la vanguardia antillana, en los principios y concepciones que sirvieron de fundamento y sustento a la elaboración por Martí de su avanzadísima estrategia revolucionaria para la totalidad de la sección nuestra del continente americano. Y mucho menos aún, cuando una parte importante de estas ideas -que nacían, además, de nuestras propias realidades antillanas- habían tenido, como hemos visto, una presencia imposible de ignorar, en importantes exponentes de los revolucionarios independentistas que en su propia tierra le habían precedido (y con algunos de los cuales aún habría de muy pronto de confluir, en bregar conjunto y común) en la organización y continuación del movimiento cubano de liberación.

Como todos aquellos, Martí ha tomado partido -desde muy temprano en su vida- junto al sector que aún sobrevivía (particularmente en Cuba) como el más oprimido y explotado de las sociedades antillanas: el negro sometido a la esclavitud. Su propia experiencia vital posterior durante su exilio en España, México, Guatemala, Venezuela y finalmente, a partir de 1881, en los Estados Unidos, le había llevado, además, al conocimiento y la cercanía de los hombres del trabajo, del indio, del hombre de campo, y -una vez abolida la esclavitud en Puerto Rico primero, y después en Cuba- del negro ya libre que seguía padeciendo explotación y discriminación, y ocupaba los niveles más bajos en la escala social y cultural de la sociedad cubana.

También como aquellos, tiene plena conciencia de la necesidad de una unión defensiva de los países inmediata y directamente amenazados por la acción expansiva de aquellas potencias que aspiran al predominio ("el Viejo Mundo, y el septentrión del Nuevo"; "las naciones de Europa, y la América europea"), y concibe la unión antillana como un muro o valladar capaz de detener el vertimiento foráneo, y muy particularmente el estadounidense, sobre el resto del mundo latinoamericano del cual las Antillas forman parte indisoluble. Pero en Martí -por la época histórica en que le ha correspondido enfrentar esa defensa, y por la especial y temprana situación de dependencia en que el devenir particular de su patria la ha situado en relación con la economía y el mercado norteamericano, aún antes de lograr erradicar la dominación colonial española-, hay la plena conciencia de que esa defensa ya no podrá ser solamente contra los intentos anexionistas europeos y estadounidenses, sino -sobre todo- contra los nuevos 
mecanismos de penetración y dominio económicos que desde la primera mitad de la década del ochenta los Estados Unidos están logrando poner en práctica en relación con México, la República Dominicana y, a través - desde luego- de España, con Puerto Rico y con Cuba.

Y es que Martí está siendo testigo, dentro de las entrañas mismas de los Estados Unidos, de que allí se está "en el momento de un grave cambio histórico, de trascendencia suma para los pueblos de América" (30). Se trata -dice- de "un conjunto de medidas que implican el cambio más grave que desde la guerra han experimentado acaso los Estados Unidos". Y está alertando acerca de que ello "no es más que una nueva manera de hacer, con blandura y sin desatención aparente de sus deberes republicanos, lo que allá en sueños y sin saber cómo, quiso Grant". Para él, el tratado recientemente firmado entre España y Estados Unidos compromete en forma tal a Puerto Rico y -fundamentalmente- a Cuba, "y de tan absoluta manera liga la existencia de la Isla a los Estados Unidos, que es poco menos que el vertimiento de cada uno de estos países en el otro, lo que acaso vendrá a parar, con gran dolor de muchas almas latinas, en perder para la América Española la isla que hubiera debido ser su baluarte". Como para el tratado con Cuba y Puerto Rico, también por el convenio firmado con Santo Domingo "cuanto acá (en los Estados Unidos -RA) sobra y no tiene por lo caro donde venderse, allá entrará sin derechos, como acá los azúcares". Y llega a la conclusión preveedora de que, con los métodos de penetración económica que analiza, "vendrán los Estados Unidos a ser, como que les tendrān toda su hacienda, los señores pacíficos y proveedores forzosos de todas las Antillas".

Anuncia así, con certera visión del futuro -y anticipándose en verlo tanto como Cuba se anticipa en padecer el nuevo tipo de dependencia- el riesgo de que allí "se establecerán, con capitales americanos acaso, muiltiples empresas, que ocasionarian demanda extraordinaria de artículos del único mercado donde tendría la isla crédito y dinero". Ya no se trata, por tanto, de defender a nuestras islas de renovados esfuerzos de posesión colonial, o de posibles nuevos intentos anexionistas, nunca por él descartados. Se trata ahora, en la nueva época histórica en que el sistema capitalista mundial ha entrado, de la urgencia del enfrentamiento antillano -y latinoamericano- a una basta

(30) Esta y las siguientes citas son de: MARTI, José: Obras Completas, Editorial de Ciencias Sociales, La Habana, 1975, t. 8, p. 87 [En lo sucesivo, nos referimos a esta edición como O.C., y -salvo indicación de lo contrario, los subrayados serán del autor de este trabajo]. 
entonces desconocida manera de perder la independencia. O dicho en otras palabras: se trata de intentar llegar a ser, dentro de las nuevas circunstancias históricas -y definitivamente-, no-dependientes.

También como aquellos otros hombres de la vanguardia revolucionaria antillana, Martí había conocido y repudiado $-\mathrm{y}$, por la menor edad del cubano, lo había hecho muy tempranamente (31) - la unilateralidad e incompletitud tanto del republicanismo liberal español, y europeo en general, como el de aquella república norteamericana que era considerada en la época el más completo modelo de libertades democráticas, y que -sin embargo- ya había iniciado, y se preparaba para intensificar, el despojo de las otras repúblicas, más o menos cercanas, al sur de su frontera, y a ocupar el lugar de las antiguas potencias coloniales en la posesión o el dominio de los más importantes territorios antillanos -independientes ya, o colonizados todavía-. Martí había, además, conocido desde dentro las variantes de liberalismo vigentes en México, Guatemala y Venezuela (o lo que es lo mismo, la trayeçtoria y la acción de Porfirio Díaz, Justo Rufino Barrios y Andrés Gómez), y había arribado a la determinante precisión de que la copia de formas y moldes nacidos de otras realidades (y de eficiencia aún cuestionable en esas propias realidades que les habían dado origen) llevaban en nuestras tierras a la superviviencia de estructuras económicas y sociales -"la colonia ha sobrevivido en la república" (32)- incapaces de dar solución a los graves problemas que pesaban sobre sus sociedades, especialmente sobre los grupos y sectores más desposeídos, junto a los cuales había tomado partido.

De ahí su búsqueda constante de respuestas propias a nuestros propios problemas, de formas republicanas y democráticas no copiadas de realidades ajenas, nacidas de nuestras necesidades específicas, y ajustadas a ellas, y que tiene su arranque en Martí -o mejor: deja su más temprana constancia escrita- desde los momentos iniciales, en 1871, de su primera deportación a España (33); se continúa en México

(31) Ver, en particular, su opúsculo La Repüblica española ante la Revolución cubana [O.C., t. 1], publicado en España en febrero de 1873, a menos de un mes de haber cumplido los 20 años de edad.

(32) O.C., t. 6, p. 19:

(33) "Los norteamericanos posponen a la utilidad el sentimiento. -Nosotros posponemos al sentimiento la utilidad. //Y si hay esta diferencia de organización, de vida, de ser [...], ¿cómo queréis que nosotros nos legislemos por las leyes con que ellos se legislan?// Imitemos. iNoi -Copiemos. ¡No! -Es bueno, nos dicen. Es americano, decimos. [...] Nuestra vida no se asemeja a la suya, ni debe en muchos puntos asemejarse. [...] Las leyes americanas han dado al norte alto grado de prospetidad, y lo han elevado también al más alto grado de corrupción. Lo han metalificado para hacerlo próspero. ¡Maldita sea la prosperidad a tanta costa!" [O.C., t. 21, p. 15-16]. 
durante 1875 y 1876 ("A propia historia, soluciones propias. A vida nuestra, leyes nuestras (...) Alzanse aquí conflictos que nuestra situación peculiarísima produce: discútanse aquí leyes, originales y concretas, que se estudien, y se apliquen, y estén hechas para nuestras necesidades exclusivas y especiales" (34). Y ya no se detendrá, ni entonces, ni durante toda la década del ochenta; aunque mostrará su forma más sintética, más integral, y probablemente más bella, en su ensayopropuesta "Nuestra América", publicado por primera vez en enero de 1891: "Con un decreto de Hamilton no se le para la pechada al potro del llanero. Con una frase de Siéyes no se desestanca la sangre cuajada de la raza india" (35). O como diría algo más adelante, en 1893: "Porque ni de Rousseau ni de Washington viene nuestra América, sino de sí misma" (36).

Y no se trata, en fin, de otra cosa que la búsqueda continua de una forma propia de existir, de crecer y desarrollarse: la búsqueda ininterrumpida y sostenida de un proyecto, de una propuesta autóctona, que -sin dejar a un lado la experiencia histórica de la humanidadviabilice la fundación de lo que Martí llamaba "la América nueva", a la que medía por la posibilidad de alcanzar un aceptable nivel de desenvolvimiento económico capaz de satisfacer, ante todo, las grandes carencias sociales de las que hasta entonces padecía, y de remediar las grandes desigualdades con cuyo peso habían históricamente cargado los grupos y clases más preteridos de nuestras sociedades. Para ello, hay que ayudar "a llenar nuestras tierras de hombres originales, criados para ser felices en la tierra en que viven, y vivir conforme a ella, sin divorciarse de ella, ni vivir infecundamente en ella, como ciudadanos retóricos, o extranjeros desdeñosos nacidos por castigo en esta otra parte del mundo. El abono se puede traer de todas partes; pero el cultivo se ha de hacer conforme al suelo. A nuestros niños los hemos de criar para hombres de su tiempo, y hombres de América" (37). Valga decir: hombres con una manera propia de existir.

Así, por una parte, está la comprensión martiana de la ineficacia e insuficiencia de los modelos ajenos para permitir a nuestros pueblos romper con la condición de dependencia que ha sobrevivido en la república, y encontrar caminos propios (que no por propios deban excluir la incorporación de toda experiencia útil, venga de donde

(34) Ibíd., t. 6, p. 312.

(35) Ibîd., p. 17.

(36) Ibid., t. 8, p. 244.

(37) Ibid., t. 20, p. 147. 
venga) para alcanzaŕ el grado de desarrollo que las formas copiadas han impedido.

Por otra parte, está la urgencia de unirse para evitar dar paso -de manera impuesta, o con la complicidad de los que han detentado en nuestros pueblos el monopolio de la riqueza y la cultura- a las nuevas formas de absorción que se ciernen sobre la seción nuestra del continente.

Y por un tercer costado, está la necesidad -y la justicia- de hacer de las amplias masas de nuestros pueblos no sólo principales (aunque no exclusivos) beneficiarios del desarrollo a que aspira, sino de hacerlas -además- importantes coprotagonistas de la defensa y el avance de las respectivas patrias nativas, y de la patria grande mayor.

$Y$ es ahora que puede cobrar completitud nuestra comprensión de la estrategia revolucionaria continental que concibe y propone: porque, a la altura de su tiempo americano, tanto la probabilidad mayor de detener ese avance imperialista que ha entendido (y que por su nombre ha denunciado), como la posibilidad más cercana de ensayar proyectos propios de desenvolvimiento general, están presentes, precisamente, en la región hacia donde se encamina con pasos más agresivos el nuevo tipo de expansión.

Ciertamente, aún en el área antillana, "ahora, cuando ya no hay esclavitud con que excusarse, está en pie la liga de la Anexión", y se procura nuevamente la de Haití y Santo Domingo, se tantea la venta de Cuba en Madrid, "y en las Antillas Menores, dan cuenta incesante los diarios del norte, del progreso de la idea anexionista", a la vez que "adquieren los Estados Unidos, en virtud de la guerra civil que fomentaron, la península de San Nicolás en Haitî" (38).

Pero es también allí donde sombrea ahora el peligro mayor; donde el creciente poderío norteamericano amenaza más directamente con lograr "restablecer con otros métodos y nombres el sistema imperial, por donde se corrompen y mueren las repúblicas" (39), cuando aún Cuba y Puerto Rico no han logrado siquiera expulsar de su tierra al antiguo poder colonial español.

$Y_{i}$ aparece entonces con toda su fuerza en Martí -como en sus antecesores, y en sus propios contemporáneos, de la vanguardia revolucionaria antillana de la segunda mitad del XIX- la siempre presente idea de la unión defensiva y protectora de nuestras islas. Sólo que en

(38) Ibíd., t. 6, p. 62.

(39) Ibid., p. 165. 
él no aparecerá -que la vigilancia del vecino poderoso ya no lo permitiría- bajo la forma de unificación formal, o confederación. En efecto, para Martí, "no aparece que la seguridad de las Antillas, ojeadas de cerca por la codicia pujante, dependa tanto de la alianza ostentosa y, en lo material, insuficiente, que provocase reparos y justificara la agresión, como la de la unión sutil, y manifiesta en todo, sin el asidero de la provocación confesa, de las islas que han de sostenerse juntas, o juntas han de desaparecer, en el recuento de los pueblos libres" (40).

Porque para Martí está claro que ahora -entre otros motivos- "por el temor de acarrearse la enemiga del vecino hostil, pudieran venir a apartarse, en cuanto cayese en forma cerrada su unión natural, la tres islas que, en lo esencial de su independencia y en la aspiración del porvenir, se tienden los brazos sobre los mares, y se estrechan ante el mundo, como tres tajos de un mismo corazón sangriento, como tres guardianes de la América cordial y verdadera, que sobrepujará al fin a la América ambiciosa, como tres hermanas" (41).

Ahora, la lucha por la expulsión definitiva del colonialismo español de Cuba y Puerto Rico ya no tendrá solamente el objetivo, a ella siempre unido en Martí, de "aprovechar la libertad en beneficio de los humildes, que son los que han sabido defenderla" (42). Ahora tendrá también la función primordial -que la convierte en el primer paso de su estrategia revolucionaria continental- de permitir, con la fundación de las dos nuevas repúblicas de absoluta independencia, la instauración de un proyecto republicano capaz de ensayar y proveer las soluciones propias que tanto las islas antillanas como los países ya republicanos de la parte nuestra de América requieren y reclaman.

De ahí que las dos tierras de Cuba y Puerto Rico fueran, para Martí, "precisamente, indispensables para la seguridad, independencia y carácter definitivo de la familia hispanomericana en el continente" (43); de ahí que la guerra revolucionaria por la independencia de ambas sería para él, sin duda, "servicio oportuno que el heroísmo juicioso de las Antillas presta a la firmeza y trato justo de las naciones americanas, y al equilibrio aún vacilante del mundo" (44), en estrecha coordinación solidaria con las repúblicas hermanas de Santo Domingo y Haití.

(40) Ibid., t. 4, p. 405.

(41) Ibid.

(42) Ibid., t. 1, p. 212.

(43) Ibid., t. 2, p. 373.

(44) Ibid., t. 4, p. 101. 
Y porque grande estaba llamado a ser el papel que debían desempeñar "esas dos islas de nombre diverso que pelearán mañana con un mismo corazón, que se defenderán con un mismo brazo, que se fundarán con un mismo pensamiento" (45), muy grave había de ser la labor a desarrollar por los hombres que lo lograsen: por "los fundadores cautos de edificio tan complicado y riesgoso como es una nación" (46).

La disyuntiva es ya clara a la altura de su tiempo: y de la magnitud "de los deberes mayores que la geografía, la vecindad temible y el problema del continente y de la época nos imponen" a Puerto Rico y a Cuba, viene la necesidad y trascendencia de "los métodos nuevos, serios y respetables que nos exigen desde el nacer estos deberes" (47) en las dos repúblicas que por la revolución se han de fundar. Y por ello, porque mucho se ha de ordenar, mucho se ha de crear, y con mucha y sabia cautela se han de organizar las dos nuevas sociedades republicanas, "no a mano ligera, sino como con conciencia de siglos, se ha de componer la vida nueva de las Antillas redimidas. Con augusto temor se ha de entrar en esa grande responsabilidad humana. Se llegará muy alto, por la nobleza del fin; o se caeará muy bajo, por no haber sabido comprenderlo. Es un mundo lo que estamos equilibrando: no son sólo dos islas las que vamos a libertar" (48).

Y señalaba Martí -ante la corta visión de aquellos que eran incapaces de comprender el alcance estratégico de la lucha que se avecinaba- la ceguera. y pequeñez de quienes intrigaban contra la magna obra revolucionaria, e intentaban -precisamente por el carácter verdaderamente popular de las fuerzas sociales que podían llevarla a cabo"acusar de demagogia, y de lisonja a las multitudes, esta obra de previsión continental" (49).

Cobra entonces nueva magnitud y nueva vigencia $-\mathrm{y}$ sintetiza y resume medio siglo de entrega y esfuerzos de los hombres que integraron aquella vanguardia revolucionaria antillana de la segunda mitad del XIX- el reclamo martiano de unión sutil antillana para culminar la obra de los precursores que la iniciaron sobre la base de los mismos principios, y con los mismos puntos de partida. Ahora, en efecto, son ya momentos en que "la independencia de Cuba y Puerto Rico no es

(45) Ibid., t. 2, p. 258.

(46) Ibid., p. 257.

(47) Ibíd.

(48) Ibid., t. 3, p. 142.

(49) Ibid. 
sólo el medio único de asegurar el bienestar decoroso del hombre libre en el trabajo justo a los habitantes de ambas islas, sino el suceso histórico indispensable para salvar la independencia amenazada de las Antillas libres, la independencia amenazada de la América libre, y la dignidad de la república americana. ¡Los flojos, respeten: los grandes, adelante! Esta es tarea de grandes (50).

Y nunca los grandes -los antillanos eternos que conformaron la vanguardia de su tierra y de su época- dejaron solo a Martí en la obra, aún inconclusa, de lograrlo.

(50) Ibid., t. 3, p. 143 . 